\title{
The Knowledge Levels of Corrosion of Students in the Faculties of Education and Science ${ }^{1}$
}

\author{
Volkan BİLİR², M. Levent AKSU ${ }^{3}$
}

Summary

\section{INTRODUCTION}

This research, being related to the corrosion which is a hot topic and always a problem facing us, tries to analyze the knowledge of corrosion of the chemistry teacher candidates and the chemistry department students and point out the issues such as presence of problem of corrosion, its reasons and results and the ways to prevent corrosion and also arouse curiosity about corrosion among the students.

\section{METHOD}

The multiple-choice achievement test consisting of 20 items with 5 options was applied to the sample group of the study and the evaluation was done by giving " 1 " point to correct answers and " 0 " point to wrong and blank answers. ANOVA test was applied to the scores that the students in the faculties of education and science took from the corrosion achievement test. The significance level was taken as 0.05 in comparisons.

\section{FINDINGS AND COMMENTS}

As seen in Table 2, it was found out that there was a significant difference among the classes in terms of the knowledge levels of corrosion of the students in the department of chemistry teaching $[\mathrm{F}(3-101)=5.846, \mathrm{p}<.05]$. When the achievement test scores of the students were analyzed, it was seen that the knowledge levels of corrosion of the students were low.

When Table 3 was analyzed, it was understood that there was a significant difference among the classes in terms of the knowledge levels of corrosion of the students in the department of chemistry $[\mathrm{F}(3-234)=4.153, \mathrm{p}<.05]$. The knowledge levels of corrosion of the students in the faculty of science were highly low, too.

\section{SUGGESTIONS}

When the living conditions of nowadays are taken into consideration, metal materials are available in every part of our life and this case raises the importance of corrosion knowledge for our life. Thus, the importance of corrosion teaching increases in preschool education, primary schools, secondary schools and universities.

It is suggested that the faculties of education and science that train educators and scientists give corrosion education.

Since the knowledge levels of corrosion of the students attending the faculty of education, chemistry teaching and faculty of science, chemistry department are highly low, it is suggested that the corrosion subject be taught as a separate course in these faculties.

\footnotetext{
${ }^{1}$ This manuscript was produced from the dissertation prepared by Volkan Bilir in the consultancy of Prof. Dr. Mehmet Levent Aksu at Gazi University, Graduate School of Educational Science, Department of Chemistry Teaching.

${ }^{2}$ The Rectorship of Düzce Üniversitesi, volkanbilir@duzce.edu.tr

${ }^{3}$ Prof. Dr. Gazi University, Faculty of Education, $\underline{\text { maksu@gazi.edu.tr }}$
} 